\title{
İndiyum Oksit Nanoyapılarının Elektrokimyasal Sentezi Ve İndiyum Oksit/Kadmiyum Sülfür Kuantum Nokta Duyarlı Güneş Pillerinin Tasarımı
}

\author{
Emir Çepni ${ }^{1 *}$, Tuba Öznülüer Özer ${ }^{2}$, Ümit Demir $^{3}$ \\ 1* Atatürk Üniversitesi, Mühendislik Fakültesi, Elektrik - Elektronik Mühendisliği Bölümü, Erzurum, Türkiye, (ORCID: 0000-0001-8738-1157), \\ emircepni@atauni.edu.tr \\ ${ }^{2}$ Atatürk Üniversitesi, Fen Fakültesi, Kimya Bölümü, Erzurum, Türkiye (ORCID: 0000-0001-5148-2984), tozkim@atauni.edu.tr \\ ${ }^{3}$ Gebze Teknik Üniversitesi, Temel Bilimler Fakültesi, Kimya Bölümü, Kocaeli, Türkiye (ORCID: 0000-0002-3123-8594), demiru@gtu.edu.tr
}

(International Conference on Design, Research and Development (RDCONF) 2021 - 15-18 December 2021)

(DOI: 10.31590/ejosat.1040289)

ATIF/REFERENCE: Çepni, E., Öznülüer Özer, T. \& Demir U. (2021). İndiyum Oksit Nanoyapılarının Elektrokimyasal Sentezi ve İndiyum Oksit/Kadmiyum Sülfür Kuantum Nokta Duyarlı Güneş Pillerinin Tasarımı. Avrupa Bilim ve Teknoloji Dergisi, (32), 657-662.

$\ddot{\mathbf{O} z}$

Dünyada hızla gelişen teknoloji ile birlikte çoğalan enerji ihtiyacını karşılamak için alternatif enerji kaynaklarının araştırılması, son yıllarda özellikle güneş pillerine olan ilgiyi oldukça arttırmıştır. Bu çalışmada, literatürde ilk defa dönüşüm verimliliği yüksek kuantum nokta duyarlı güneş pilleri için kadmiyum sülfür (CdS) kuantum noktalarıyla dekore edilmiş indiyum oksit $\left(\operatorname{In}_{2} \mathrm{O}_{3}\right)$ esaslı fotoanotların sentezi gerçekleştirildi. Sentezlenen materyalin yapısal, morfolojik ve fotoelektrokimyasal karakterizasyonlarında X-1şını fotoelektron spektroskopisi, X-1̧̧ını difraktometresi, Enerji dağılımlı X-1şını spektroskopisi, Taramalı elektron mikroskopi teknikleri ve fotoakım yoğunluğu ölçümleri kullanıldı. Karakterize edilen fotoanotlar kullanılarak kuantum nokta duyarlı güneş pilleri tasarlandı ve temel kalite parametreleri olan dolum faktörü ile dönüşüm verimliliği fotoakım yoğunluğu-voltaj eğrileriyle hesaplandı. Ölçümler sonucunda tasarlanan güneş pillerinin $0.324^{\prime}$ lük bir dolum faktörüne ve $\% 0.22^{\prime}$ lik bir dönüşüm verimliliğine sahip olduğu belirlendi.

Anahtar Kelimeler: Indiyum oksit, Elektrokimyasal sentez, Kuantum nokta duyarlı güneş pilleri

\section{Electrochemical Synthesis Of Indıum Oxıde Nanostructures And Desıgn Of Indıum Oxıde/Cadmıum Sulfide Quantum Dot Sensitızed Solar Cells}

\begin{abstract}
The exploration for alternative energy sources in order to meet the increasing energy need in the world with the rapidly developing technology has increased the interest especially in solar cells in recent years. This study reports the synthesis of indium oxide ( $\left.\mathrm{In}_{2} \mathrm{O}_{3}\right)$ based photoanodes decorated with cadmium sulfide $(\mathrm{CdS})$ quantum dots to be used for the first time in the literature in quantum dot sensitized solar cells with high conversion efficiency. The X-ray photoelectron spectroscopy, X-ray powder diffraction spectroscopy, Energy dispersive X-ray spectroscopy, Scanning electron microscopy and photocurrent density measurements were used for the structural, morphological and photoelectrochemical characterization of the synthesized material. Quantum dot sensitized solar cells were designed using the characterized photoanodes and the basic quality parameters, the filling factor, and the conversion efficiency were calculated with the photocurrent density-voltage curves. As a result of the measurements, it has been determined that the designed solar cells have a filling factor of 0.324 and a conversion efficiency of $0.22 \%$.
\end{abstract}

Keywords: Indium oxide, Electrochemical synthesis, Quantum dot sensitized solar cells

*Sorumlu Yazar: emircepni@atauni.edu.tr 


\section{Giriş}

Dünya genelinde artan enerji ihtiyacı, bu ihtiyacı karşılayan fosil yakıt rezervlerinin azalması ve küresel ısınma gibi sorunlar araştırmacıları yenilenebilir, ucuz ve temiz enerji kaynakları arayışına itmektedir. Hidroelektrik ve rüzgar enerjisi gibi sürekli var olan yenilenebilir enerji kaynakları arasında güneş 1şı̆̆ güvenilir, erişilebilir, temiz ve tükenmeyen bir enerji kaynağ 1 olarak öne çıkmaktadır. Fotovoltaik hücreler kullanılarak güneş enerjisinin elektrik enerjisine dönüştürülmesi artan enerji ihtiyacının karşılanması ve gelecekte oluşabilecek enerji krizlerinin çözümü için en uygun yöntemlerden birisidir (Kamat, 2007: 2834-2860). Güneş, gezegenimize küresel enerji ihtiyacının 10000 kat daha fazlasını sağlamaktadır. Literatürde, dünya yüzeyinin $\% 0.1$ 'inin $\% 10$ 'luk enerji dönüşüm verimliliğine sahip fotovoltaik güneş pilleri ile kaplanması durumunda dünya nüfusunun ihtiyaç duyduğu tüm enerjinin güneşten karşılanabileceği bildirilmiştir (Dresselhaus ve Thomas, 2001: 334-337).

Kuantum nokta duyarlı güneş pilleri (QDSSC) üzerine yapılan araştırmalar son yıllarda giderek artmaktadır. Kuantum noktalarının (QD) dönüşüm verimliliğini arttırabilmesindeki temel etken, nano ölçekte sentezlenen bileşik yarı iletkenlerin kuantum sinırlaması nedeniyle absorpsiyon spektrumlarda boyuta bağlı değişikliklerin yapılabilmesidir (Anikeeva vd., 2009: 25322536). Bu nedenle, tek bir enerji bandı aralığına sahip yarı iletken malzeme esaslı güneş pillerinden farklı olarak, nano boyut kontrolü ile sentezlenen farklı boyut ve tipte QD'lar esaslı güneş pilleri, güneş ışınlarının tüm spektrumunu toplama kapasitesine sahip olabilir (Schaller vd., 2005: 189-194; Beard vd., 2014: 951954). QDSSC'lerin geleneksel silikon bazlı güneş pillerine kıyasla enerji dönüşüm verimleri oldukça düşüktür. Bu tip güneş pillerinde dönüşüm verimini etkileyen en önemli faktörler fotoanot olarak kullanılan yarı iletken metal oksitin türü ve morfolojik yapısıdır. Fotoanot hem geniş bir bant aralığına sahip olmalı hem de kullanılan elektrolit içinde kararlı olmalıdır. Titanyum dioksit $\left(\mathrm{TiO}_{2}\right)$ ve çinko oksit $(\mathrm{ZnO})$ QDSSC için literatürde en çok araştırılan fotoanotlardır (Badawi vd., 2020: 726; Singh vd., 2017: 16-23; Tyagi vd., 2021: 111014; Latif vd., 2020: 617-623; Jo vd., 2021: 159527). Bu fotoanotlara alternatif olarak kullanılabilecek metal oksitlerden biri olan indiyum oksit $\left(\mathrm{In}_{2} \mathrm{O}_{3}\right)$, geniş bir bant aralığına $(\mathrm{Eg} \approx 3.7 \mathrm{eV})$ ve olağanüstü optiksel özelliklere sahiptir (Liu vd., 2005: 5276-5277). Süperkapasitör (Chen vd., 2009: 043113), FET (Zou vd., 2013: 804-810), şeffaf ince film transistör (Shen vd., 2011: 771-775), panel ekran (Jia vd., 2003: 4146-4148), LED (Chen vd., 2011: 165101) ve gaz sensörü (Kim vd., 2015: 4572-4582) gibi çeşitli alanlarda yaygın olarak kullanılmaktadır. $\mathrm{In}_{2} \mathrm{O}_{3}$ gelişmiş elektriksel özellikleri ve geniş spesifik yüzey alanı ile enerji depolama alanında giderek daha fazla araştırılmaktadır. Literatürde farklı morfolojilere sahip $\operatorname{In}_{2} \mathrm{O}_{3}$ nanoyapılar kimyasal buhar depozisyonu (Tuzluca vd., 2017: 62-68), hidrotermal sentez (Padmanathan vd., 2016: 4820-4830), termal buharlaştırma (Jian vd., 2015: 123007) ve karbotermal indirgeme (Huang vd., 2007: 5137-5140) yöntemleri kullanılarak sentezlenmiştir. Bu sentez yöntemlerine kıyasla elektrokimyasal yöntem; depozisyon süresi ve potansiyeli, çözelti bileşimi, elektrot materyalinin değiştirilmesi gibi çeşitli değişkenlerin ayarlanmasıyla yapı ve boyut kontrolüne olanak verdiği için diğer yöntemlere göre daha avantajlıdır. Özellikle substrat yüzeyinde doğrudan malzeme oluşumuna imkan tanıması bu yöntemi pratik kılmakla birlikte; ağır kimyasallar ve yüksek sıcaklık/basınç ortamına ihtiyaç e-ISSN: 2148-2683 duyulmaması da ticarileşme anlamında maliyeti düşürmektedir. Literatürde $\mathrm{In}_{2} \mathrm{O}_{3}$ nanoyapılarının kadmiyum sülfür (CdS) QD'lar ile dekore edilerek QDSSC'lerde fotoanot olarak kullanımını inceleyen herhangi bir çalışma bildirilmemiştir.

$\mathrm{Bu}$ çalışmada, geniş bant aralığına ve etkin yüzey morfolojisine sahip $\mathrm{In}_{2} \mathrm{O}_{3}$ nanoyapıları flor katkılı kalay oksit kaplı cam elektrot (FTO) yüzeyinde elektrokimyasal yöntemle sentezlenmiştir. Karakterize edilen $\operatorname{In}_{2} \mathrm{O}_{3}$ nanoyapılarının yüzeyi, ardışık iyonik tabaka adsorpsiyon ve reaksiyonu (SILAR) yöntemi kullanılarak CdS QD'lar ile dekore edilmiştir. Dekorasyon işlemi sonrasında karakterizasyonu tamamlanan FTO- $\mathrm{In}_{2} \mathrm{O}_{3} / \mathrm{CdS}$ elektrotlarının fotoanot olarak kullanıldı $\breve{g}_{1}$ QDSSC'ler tasarlanmıştır. Tasarımda FTO yüzeyinde elektrokimyasal yöntemle sentezlenen bakır(I) sülfür $\left(\mathrm{Cu}_{2} \mathrm{~S}\right)$ elektrotları karşıt elektrot, polisülfit çözeltisi ise redoks elektroliti olarak kullanılmıştır. Tasarlanan QDSSC'lerin fotovoltaik özellikleri, AM 1.5 1şıması (100 mW.cm $\left.{ }^{-2}\right)$ altında elde edilen fotoakım yoğunluğu-voltaj (J-V) eğrileriyle karakterize edilmiştir. Bu J-V eğrileri kullanılarak QDSSC'lerin temel kalite

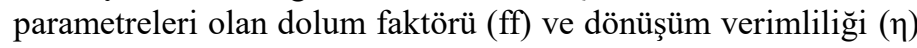
hesaplanmıştır.

\section{Materyal ve Metot}

Bütün elektrokimyasal sentez ve ölçümler, tam kalibre edilmiş bir GAMRY Reference $600+$ potansiyostat cihazına bağlı üç elektrotlu bir elektrokimyasal hücre ile oda sıcaklığında ve ortam koşulları altında yapılmıştır. FTO- $\mathrm{In}_{2} \mathrm{O}_{3} / \mathrm{CdS}$ fotoanotlarının ve FTO- $\mathrm{Cu}_{2} \mathrm{~S}$ karşıt elektrotlarının sentezi için çalışma elektrodu olarak FTO (elmas kalemle yüzeyinde $0.25 \mathrm{~cm}^{2}$ aktif alan şekillendirilmiş (Şekil 1a)), referans elektrot olarak $\mathrm{Ag} / \mathrm{AgCl}(3 \mathrm{M} \mathrm{KCl}$ ile doyurulmuş) ve karşıt elektrot olarak platin (Pt) tel $\left(\approx 1 \mathrm{~cm}^{2}\right.$ alana sahip) kullanılmıştır. Elektrokimyasal sentez işlemleri öncesinde kullanılacak FTO elektrotlar ultrasonik banyoda 15 'er dakika boyunca sirasiyla etanol ve saf suda bekletilerek temizlenmiş ve Argon (Ar) gazı ile kurutulmuştur.

Sentezlenen fotoanotların yapısal ve morfolojik karakterizasyonu için X-1şını fotoelektron (Al K $\alpha$ X-ray (1486.6 eV)) spektroskopisi (XPS), Rigaku miniflex X-1şını (Cu-Ka $(\lambda=15.405 \AA)$ difraktometresi (XRD), Enerji dağılımlı X-1şını spektroskopisi (EDS) ve FEI quanta taramalı elektron mikroskobu (FE-SEM) kullanılmıştır. Fotoelektrokimyasal karakterizasyon ise AM 1.5 1şıması (100 mW.cm $\left.{ }^{-2}\right)$ altında fotoakım yoğunluğu ve J-V ölçümleri ile yapılmıştır.

\section{1. $\mathrm{In}_{2} \mathrm{O}_{3}$ Nanoyapılarının Elektrokimyasal Sentezi}

$\mathrm{In}_{2} \mathrm{O}_{3}$ nanoyapılarının FTO elektrot yüzeyinde elektrokimyasal sentezi için $0.01 \mathrm{M} \mathrm{InCl}_{3}$ ve $0.1 \mathrm{M} \mathrm{KCl}$ içeren elektrolit çözeltisi kullanılmıştır. Sentez işlemi öncesinde 15 dakika boyunca oksijen $\left(\mathrm{O}_{2}\right)$ gazı geçirilen çözeltiden $-1.2 \mathrm{~V}$ 'da 10 dakika süreyle depozisyon yapılmıştır. Depozisyon işlemi sonrasında oluşan hidroksit yapılarının oksit forma dönüşümü için $400^{\circ} \mathrm{C}$ 'de 30 dakika tavlama yapılmış ve FTO- $\operatorname{In}_{2} \mathrm{O}_{3}$ elektrotları elde edilmiştir (Şekil 1b).

\subsection{CdS QD Dekorasyonu}

Elektrokimyasal yöntemle sentezlenen $\operatorname{In}_{2} \mathrm{O}_{3}$ nanoyapılarının yüzeyi, CdS QD'larla SILAR yöntemi kullanılarak dekore edilmiştir. SILAR yönteminde $\mathrm{Cd}^{+2}$ kaynağı olarak $0.05 \mathrm{M}$ $\mathrm{Cd}\left(\mathrm{CH}_{3} \mathrm{COO}\right)_{2}, \mathrm{~S}^{-2}$ kaynağ 1 için ise $0.05 \mathrm{M} \mathrm{Na} 2 \mathrm{~S}$ sulu çözeltileri ayrı ayrı hazırlanmıştır. FTO- $\operatorname{In}_{2} \mathrm{O}_{3}$ elektodu öncelikle 20 saniye 658 
süreyle $\mathrm{Cd}\left(\mathrm{CH}_{3} \mathrm{COO}\right)_{2}$ çözeltisine daldırılmış ve elektrot yüzeyine zayıf bir şekilde tutunan türlerin uzaklaştırılması için 10 saniye boyunca saf su ile yıkanmıştır. Ardından elektrot $\mathrm{Na}_{2} \mathrm{~S}$ çözeltisine daldırılmış ve yüzeye tutunan türlerin QD yapısını oluşturmak üzere kimyasal reaksiyonu gerçekleştirilmiştir. Son adımda FTO- $\mathrm{In}_{2} \mathrm{O}_{3}$ elektrot yüzeyine düzensiz olarak tutunan türlerin uzaklaştırılması amacıyla yine 10 saniye boyunca saf su ile yıkama işlemi gerçekleştirilmiştir. $\mathrm{Bu}$ prosedür, SILAR yöntemi için bir çevrim olarak tanımlanmıştır ve fotoelektrokimyasal karakterizasyon ölçümleri kapsamında tekrarlayan 20 çevrim sonucunda $\mathrm{FTO}-\mathrm{In}_{2} \mathrm{O}_{3} / \mathrm{CdS}$ fotoanotları elde edilmiştir (Şekil 1c).

\subsection{Cu2S Karşıt Elektrotlarının Hazırlanması}

FTO- $\mathrm{Cu}_{2} \mathrm{~S}$ elektrotları saf suda çözünmüş $0.05 \mathrm{M} \mathrm{CuCl}_{2}, 0.05$ $\mathrm{M}$ tiyoüre ve $0.1 \mathrm{M} \mathrm{NaCl}$ içeren karışım çözeltisinden $-0.85 \mathrm{~V}$ sabit potansiyelinde 15 dakika süren tek adımlı bir katodik elektrodepozisyon yöntemi kullanılarak hazırlanmıştır. Elektrodepozisyon işlemi sonrasında saf su ile yıkanan elektrotlar Ar gazı ile kurutularak QDSSC'lerinde karşıt elektrot olarak kullanıma hazır hale getirilmiştir (Şekil 1d).

\subsection{QDSSC'lerin tasarımı}

Tasarlanan QDSSC'lerde redoks elektroliti olarak ultra saf suda çözünmüş $1 \mathrm{M} \mathrm{Na} 2 \mathrm{~S}, 1 \mathrm{M} \mathrm{S}$ ve $0.1 \mathrm{M} \mathrm{KCl}$ içeren polisülfit çözeltisi kullanılmıştır. FTO- $\operatorname{In}_{2} \mathrm{O}_{3} / \mathrm{CdS}$ elektrotunun aktif yüzeyinde redoks elektrolitinin sızmasını engellemek için $\approx 40$ $\mu \mathrm{m}$ kalınlığında bir parafilm ayırıcı kullanılmış ve hazırlanan polisülfit çözeltisi bu yüzeye damlatılmıştır. Ardından 19 mm'lik iki adet klips kullanılarak FTO- $\mathrm{In}_{2} \mathrm{O}_{3} / \mathrm{CdS}$ ile $\mathrm{FTO}-\mathrm{Cu}_{2} \mathrm{~S}$ elektrotları bir bütün haline getirilmiş ve QDSSC tasarımı tamamlanmıştır (Şekil 1e,f).

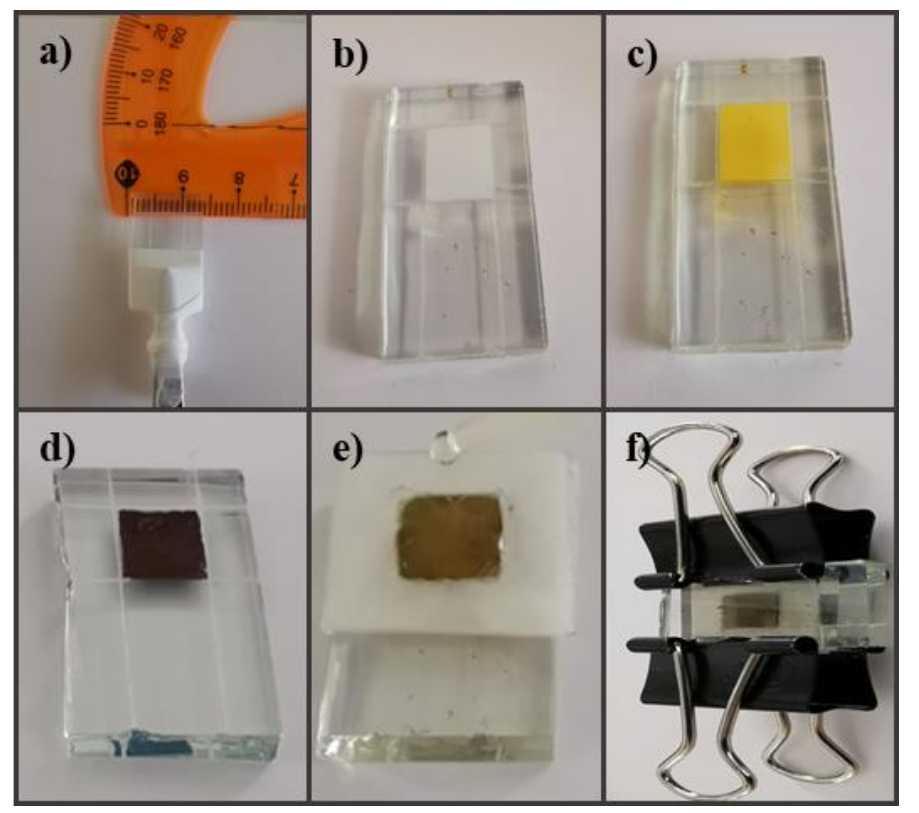

Şekil 1. FTO (a), FTO- $\mathrm{In}_{2} \mathrm{O}_{3}$ (b), FTO- $\mathrm{In}_{2} \mathrm{O}_{3} / \mathrm{CdS}$ (c), FTO- $\mathrm{Cu}_{2} \mathrm{~S}$ elektrotları (d) ve QDSSC tasarımı (e,f).

\section{Araştırma Sonuçları ve Tartışma}

\subsection{Yapısal ve Morfolojik Karakterizasyon}

Elektrokimyasal olarak sentezlenen $\mathrm{In}_{2} \mathrm{O}_{3}$ nanoyapılarının SILAR metodu kullanılarak CdS QD'larıyla dekorasyonu sonrasında elde edilen FTO- $\operatorname{In}_{2} \mathrm{O}_{3} / \mathrm{CdS}$ fotoanotlarının yapısal ve morfolojik karakterizasyonlarında çeşitli spektroskopi teknikleri kullanılmıştır. Fotoanotların kristal yapısını belirlemek üzere XRD tekniği kullanılarak alınan difraktogram Şekil 2'de verilmiştir.

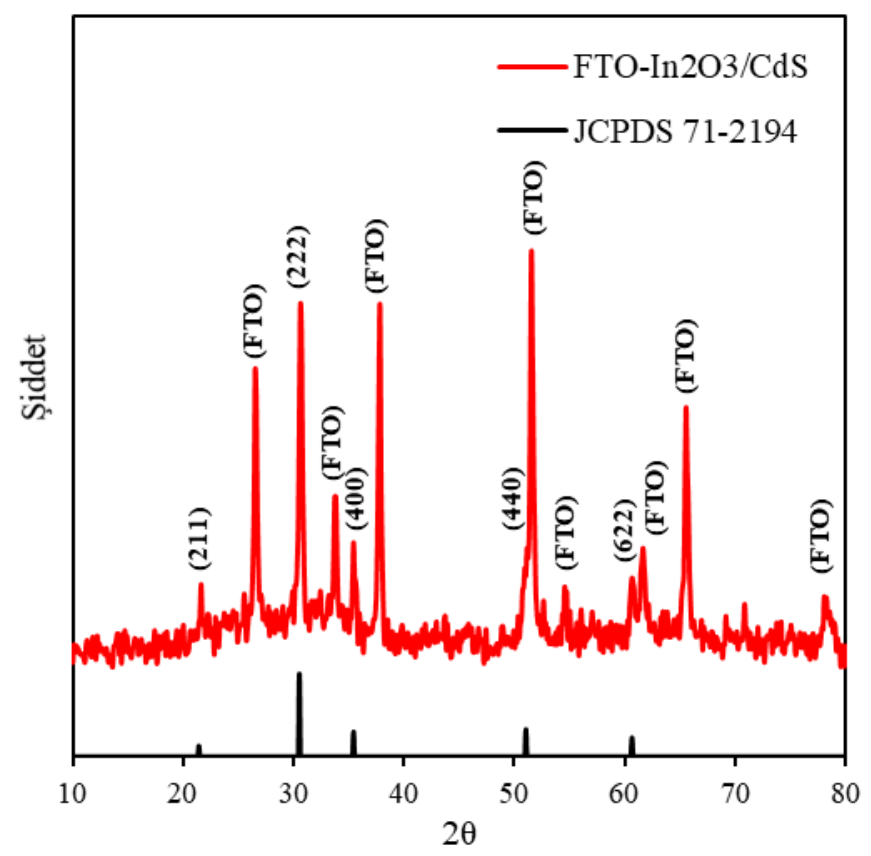

Şekil 2. FTO- $\mathrm{In}_{2} \mathrm{O}_{3} / \mathrm{CdS}$ elektrotlarının XRD difraktogramı.

Elde edilen difraktogramda $2 \theta=21.5^{\circ}, 30.6^{\circ}, 35.5^{\circ}, 51^{\circ}$ ve $60.6^{\circ}$ 'de gözlemlenen kırınım pikleri sırasıyla $\operatorname{In}_{2} \mathrm{O}_{3}$ (211), (222), (400), (440) ve (622) kristal düzlemlerine aittir. CdS QD yapısına ait kırınım piki ise dedektör hassasiyetine bağlı olarak tespit edilememiştir. Difraktogramda metalik In veya hidroksit formuna ait kırınım piklerine rastlanmaması $\operatorname{In}_{2} \mathrm{O}_{3}$ nanoyapılarının elektrokimyasal olarak saf kristal yapıda başarıyla sentezlenebildiğini desteklemektedir.

FTO- $\mathrm{In}_{2} \mathrm{O}_{3} / \mathrm{CdS}$ fotoanotlarının yapısal karakterizasyonunda yüzey kompozisyonu XPS ölçümleriyle analiz edilmiştir. Şekil 3a-d'de In 3d, O 1s, Cd 3d ve S 2p bölgeleri için elde edilen XPS çekirdek spektrumları mevcuttur. In $3 \mathrm{~d}$ bölgesinde 452.2 ve 444.4 eV'ta tespit edilen fotoelektronlar, $\mathrm{In}_{2} \mathrm{O}_{3}$ 'ün sirasiyla In $3 \mathrm{~d}_{3 / 2}$ ve In $3 \mathrm{~d}_{5 / 2}$ değerlik durumları ile ilişkilendirilir (Rumble vd., 1992: 241-246). O 1s spekturumunda 529.5 eV'taki pik In-O-In yapısındaki oksijen bağlarına karşılık gelirken, $531.2 \mathrm{eV}$ 'ta gözlenen tepe metal oksit yığınındaki oksijen boşluklarına atfedilebilir (Shinde vd., 2014: 5490-5498). Cd elementinin 3d enerji bölgesine ait spektrumda $\mathrm{Cd} 3 \mathrm{~d}_{5 / 2}(405.1 \mathrm{eV})$ ve $\mathrm{Cd} 3 \mathrm{~d}_{3 / 2}$ $(411.9 \mathrm{eV})$ bağlanma enerjilerine karşı gelen iki pik bulunmaktadır. Bu pikler arasında $6.7 \mathrm{eV}$ 'luk bir spin-yörünge ayrımı bulunmaktadır. S 2p çekirdek seviye spektrumunda 161.5 eV'taki pik ise CdS kuantum parçacıklarındaki $\mathrm{S}^{-2}$ varlığını destekler. Cd 3d ve S 2 p enerji bölgelerindeki bu spektrumlar literatür ile oldukça benzerdir (Chen vd., 2006: 177-184; Lin vd., 2010: 8717-8723). 

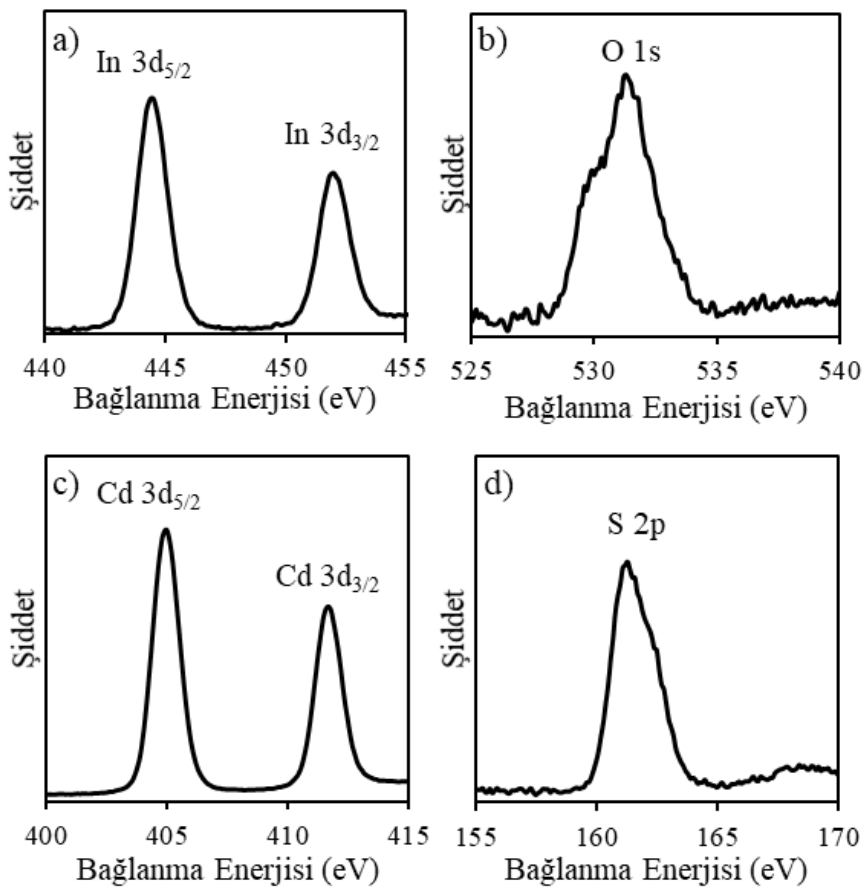

Şekil 3. FTO- $\operatorname{In}_{2} \mathrm{O}_{3} / \mathrm{CdS}$ fotoanotlarının In 3d (a), O 1s (b), Cd 3d (c) ve S $2 p$ XPS çekirdek spektrumları.

FTO- $\mathrm{In}_{2} \mathrm{O}_{3} / \mathrm{CdS}$ fotoanotlarının yüzey morfolojisinin belirlenmesi amacıyla alınan FE-SEM görüntüleri Şekil 4a,b'de verilmiştir. Elektrokimyasal yöntemle elde edilen FTO- $\operatorname{In}_{2} \mathrm{O}_{3}$ elektrotlarının yüzey morfolojisinde topak şeklinde büyüyen $\mathrm{In}_{2} \mathrm{O}_{3}$ nanoyapıları gözlemlenmiştir (Şekil 4a). FE-SEM analizleri bu yapıların elektrot yüzeyini homojen bir şekilde kapladığını ve belirli alanlarda yı̆̆ın halinde birikmediklerini destekler. Topak şeklindeki bu oluşumlara, literatürde farklı yöntemlerle sentezlenen $\mathrm{In}_{2} \mathrm{O}_{3}$ yapılarının morfolojik karakterizasyonunda rastlanmıştır (Shen vd., 2021: 3647-3653; Zhang vd., 2021: 106124). Şekil 4b'de SILAR yöntemi ile yüzeyi CdS QD'ları ile dekore edilen FTO- $\mathrm{In}_{2} \mathrm{O}_{3}$ elektrotlarının FE-SEM görüntüsü verilmiştir. Yüksek büyütme oranında alınan görüntüde $\mathrm{CdS}$ kuantum parçacıkların oldukça küçük boyutlarda ve homojen bir şekilde $\quad \mathrm{In}_{2} \mathrm{O}_{3} \quad$ nanoyapılarının yüzeyini kapladığ görülebilmektedir. Ayrıca $\mathrm{CdS}$ dekorasyonu öncesinde yüzey morfolojisi belirlenen $\operatorname{In}_{2} \mathrm{O}_{3}$ nanoyapılarında dekorasyon işlemi sonrasında kritik deformasyonlar oluşmamıştır.
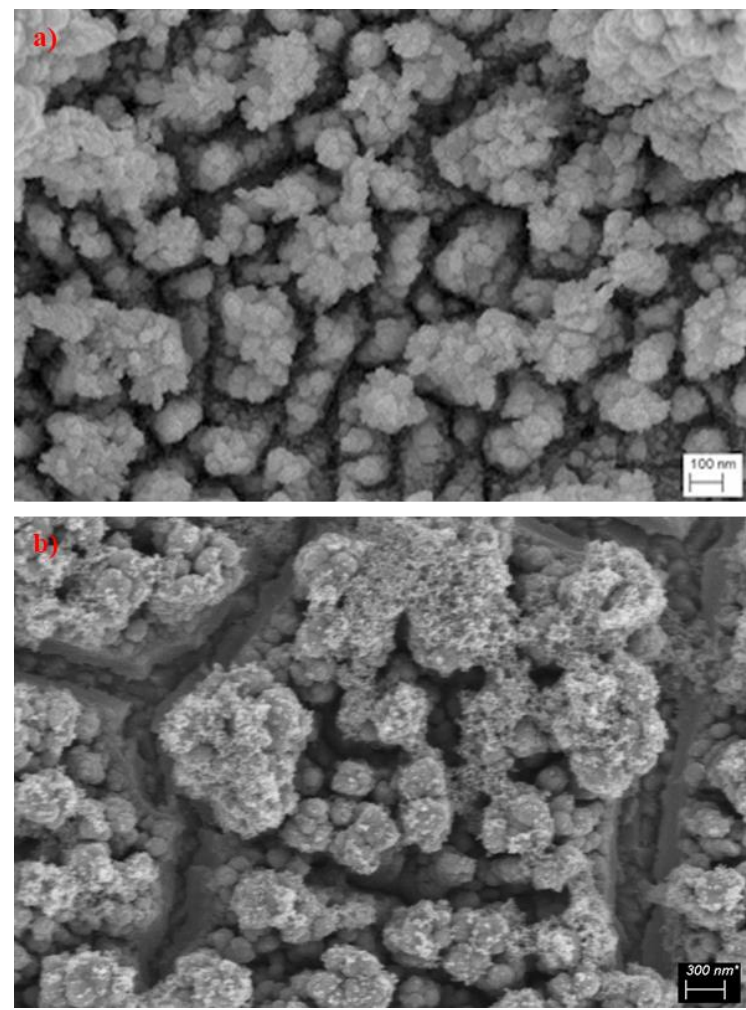

Şekil 4. FTO- $\mathrm{In}_{2} \mathrm{O}_{3}$ (a) ve FTO- $\mathrm{In}_{2} \mathrm{O}_{3} / \mathrm{CdS}$ (b) elektrotlarının FESEM görüntüleri.

Fotoanotların elementel bileşimi FE-SEM cihazına entegre çalışan EDS ölçümleriyle aydınlatılmıştır. Şekil 5'te verilen EDS spektrumunda, FTO kaynaklı zayıf piklerin yanı sıra, CdS QD yapısındaki $\mathrm{Cd}$ ve $\mathrm{S}$ pikleri ile $\mathrm{In}_{2} \mathrm{O}_{3}$ yapısını oluşturan In ve $\mathrm{O}$ pikleri de tespit edilmiştir (Şekil 5). Tespit edilen bu pikler FTO$\mathrm{In}_{2} \mathrm{O}_{3} / \mathrm{CdS}$ fotoanotlarını oluşturan In, $\mathrm{O}, \mathrm{Cd}$ ve $\mathrm{S}$ elementlerinin varlıklığını açık bir şekilde ortaya koymaktadır.

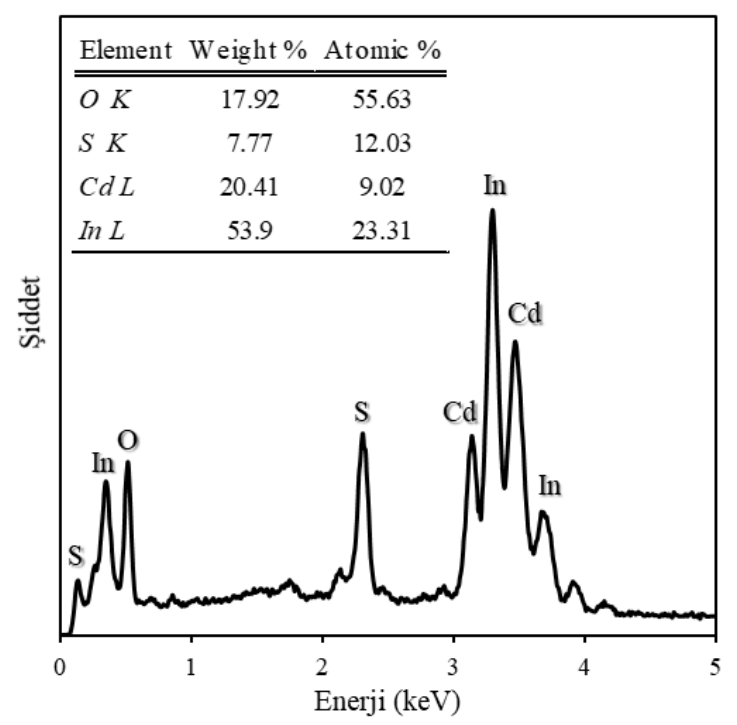

Şekil 5. FTO- $\mathrm{In}_{2} \mathrm{O}_{3} / \mathrm{CdS}$ elektrotlarının EDS spektrumu.

\subsection{Fotoelektrokimyasal Karakterizasyon}

Yapısal ve morfolojik karakterizasyonu yapılan fotoanotların fotoeelektrokimyasal özelliklerinin belirlenmesi için zamana bağlı fotoakım yoğunluğu ölçümleri yapılmıştır. Şekil 6'da FTO$\mathrm{In}_{2} \mathrm{O}_{3}$ ve farklı SILAR çevrim sayılarında CdS QD'ları ile dekore edilerek üretilmiş FTO- $\mathrm{In}_{2} \mathrm{O}_{3} / \mathrm{CdS}$ elektrotlarının AM 1.5 1şıması 
(100 mW.cm $\left.{ }^{-2}\right)$ altında elde edilen fotoakım yoğunluğu-zaman diyagramları mevcuttur. Fotoakım yoğunlukları herhangi bir reaktör veya katalizör içermeyen $0.5 \mathrm{M} \mathrm{KOH}$ sulu çözeltisi kullanılarak 10 saniyelik kesikli aydınlatma dilimlerinde ölçülmüştür. Açılan 1şıkla birlikte fotoanotların oluşturduğu fotoakım yoğunluğu hızla yükselirken, kapalı 1şık altında aniden düşmektedir. Yapılan ölçümlerinde en iyi fototepki, yaklaşık olarak $0.3 \mathrm{~mA} . \mathrm{cm}^{-2}$ fotoakım yoğunluğuna sahip 20 SILAR çevrimi ile CdS QD dekore edilen fotoanotta gözlenmiştir. Ayrıca FTO- $\mathrm{In}_{2} \mathrm{O}_{3} / \mathrm{CdS}$ elektrotlarının FTO- $\mathrm{In}_{2} \mathrm{O}_{3}$ elektroduna kıyasla ışıma altında oluşturdukları yüksek fotoakım yoğunlukları $\mathrm{CdS}$ QD varlığına atfedilir.

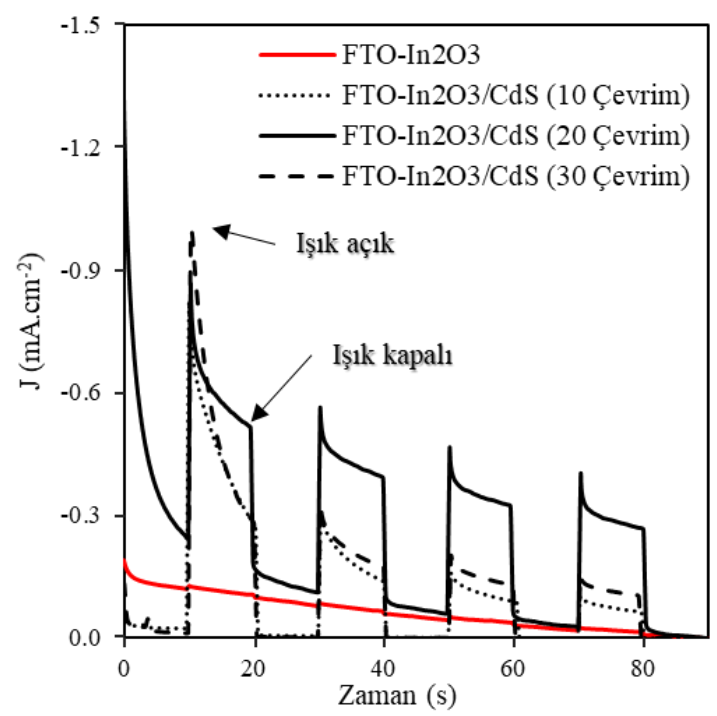

Şekil 6. FTO- $\mathrm{In}_{2} \mathrm{O}_{3}$ ve farklı SILAR çevrim sayılarında $\mathrm{CdS}$ QD'ları ile dekore edilerek üretilmiş FTO- $\mathrm{In}_{2} \mathrm{O}_{3} / \mathrm{CdS}$ elektrotlarının AM 1.5 1şıması $\left(100 \mathrm{~mW} . \mathrm{cm}^{-2}\right)$ altında elde edilen fotoakım yoğunluğu-zaman diyagramları.

Fotoakım yoğunluğu ölçümleri sonucunda yapay güneş ışımasına altında en iyi fototepkiyi oluşturan fotoanot kullanılarak QDSSC'ler tasarlanmıştır. Tasarlanan QDSSC'lerin ff ve $\eta$ parametreleri yine AM 1.5 1şıması $\left(100 \mathrm{~mW} . \mathrm{cm}^{-2}\right)$ altında $\mathrm{J}-\mathrm{V}$ ölçümü kullanılarak denklem 1 ve 2 ile hesaplanmıştır.

$$
\begin{aligned}
& f f=\frac{P \max }{P t}=\frac{J \max * V \max }{J s c * V o c} \\
& \eta=\frac{P \max }{P \text { im }}
\end{aligned}
$$

Denklemlerde ff dolum faktörünü, $P_{\max }$ maksimum güç yoğunluğunu (mW.cm-2), $\mathrm{J}_{\max }$ ve $\mathrm{V}_{\max }$ sirasiyla maksimum güce denk gelen akım yoğunluğu $\left(\mathrm{mA} . \mathrm{cm}^{-2}\right)$ ve voltajı $(\mathrm{V}), \mathrm{J}_{\mathrm{sc}}$ kısa devre akım yoğunluğunu $\left(\mathrm{mA} . \mathrm{cm}^{-2}\right), \mathrm{V}_{\mathrm{oc}}$ açık devre gerilimini (V), $\eta$ dönüşüm verimliliğini $(\%)$ ve $\mathrm{P}_{\text {in }}$ güneş 1 1şı̆̆ 1 gücünü $\left(\mathrm{mW} . \mathrm{cm}^{-2}\right)$ ifade etmektedir. Şekil 7'de tasarlanan QDSSC'lerin AM 1.5 1şıması (100 mW.cm $\left.{ }^{-2}\right)$ altında ölçülen $\mathrm{J}-\mathrm{V}$ eğrileri mevcuttur. Yapılan ölçümlerle elde edilen QDSSC parametreleri ise Tablo 1'de verilmiştir.

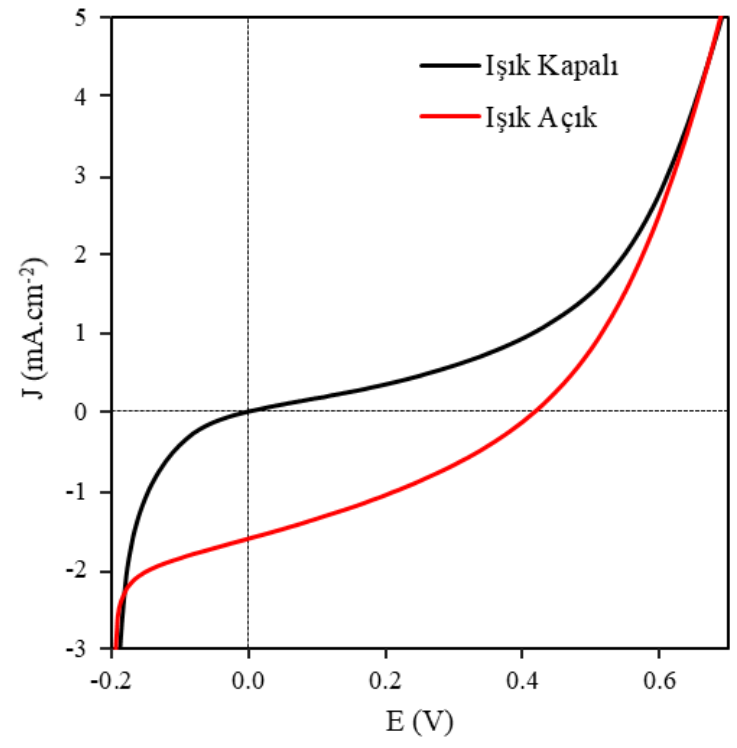

Şekil 7. Tasarlanan QDSSC'lerin ölçülen J-V eğrileri.

Tablo 1. J-V ölçümleri ile elde edilen QDSSC parametreleri

\begin{tabular}{cccccc}
\hline $\begin{array}{c}\mathbf{J}_{\text {sc }} \\
\left(\mathbf{m A} / \mathbf{c m}^{2}\right)\end{array}$ & $\begin{array}{c}\mathbf{V}_{\text {oc }} \\
(\mathbf{V})\end{array}$ & $\begin{array}{c}\mathbf{J}_{\max } \\
\left(\mathbf{m A} / \mathbf{c m}^{2}\right)\end{array}$ & $\begin{array}{c}\mathbf{V}_{\max } \\
(\mathbf{V})\end{array}$ & $\mathbf{f f}$ & $\boldsymbol{\eta}(\%)$ \\
\hline 1.603 & 0.42 & 0.91 & 0.24 & 0.324 & 0.22
\end{tabular}

J-V ölçümleri sonucunda tasarlanan QDSSC'lerin 0.324'lük bir dolum faktörüne ve \%0.22'lik bir dönüşüm verimliliğine sahip olduğu belirlenmiştir. Bu değerler CdS QD'larıyla dekore edilmiş $\mathrm{In}_{2} \mathrm{O}_{3}$ nanoyapılarının QDSSC'lerde fotoanot olarak kullanabileceğini destekler ve geliştirilmeye açıktır.

\section{Sonuç}

Sunulan çalışmada, $\operatorname{In}_{2} \mathrm{O}_{3}$ nanoyapıları basit bir elektrokimyasal yöntem ile sentezlenmiş ve SILAR tekniği kullanılarak CdS QD'ları ile dekore edilmiştir. XRD, XPS, SEM ve EDS teknikleri elde edilen materyalin yapısal ve morfolojik karakterizasyonunda kullanılmış ve materyal oluşumu desteklenmiştir. Literatürde CdS QD'lar ile dekore edilmiş $\mathrm{In}_{2} \mathrm{O}_{3}$ nanoyapılarının QDSSC'lerde fotoanot olarak kullanımını inceleyen herhangi bir çalışma bulunmamaktadır. Fotoakım yoğunluğu ve J-V ölçümleri kullanılarak yapılan fotoelektrokimyasal karakterizasyon ile bu literatür açığı kapatılmıştır. Elde edilen sonuçlar, elektrokimyasal yöntemle sentezlenen $\mathrm{In}_{2} \mathrm{O}_{3}$ nanoyapılarının SILAR yöntemi kullanılarak CdS QD'lar ile dekore edilebildiğini ve QDSSC'lerde fotoanot olarak kullanılabileceğini göstermiştir.

\section{Teşekkür}

$\mathrm{Bu}$ çalışma, finansal olarak Atatürk Üniversitesi tarafından desteklenmiş olup, QDSSC tasarımı yazarların da yer aldığ 315M421 nolu TÜBİTAK projesinden esinlenerek geliştirilmiştir. $\mathrm{Bu}$ bağlamda, araştırma için alt yapısını kullandığımız Atatürk Üniversitesi Fen Fakültesi Dekanlığı'na, TÜBITTAK'a ve XPS, SEM ve EDS ölçümleri için Atatürk Üniversitesi Doğu Anadolu Yüksek Teknoloji Araştırma Merkezi'ne (DAYTAM) teşekkürlerimizi sunarız. 


\section{Kaynakça}

Anikeeva P.O., Halpert J.E., Bawendi M.G., Bulović V. (2009). "Quantum dot light-emitting devices with electroluminescence tunable over the entire visible spectrum". Nano Letters. Say1: 9(7), s.2532-2536.

Badawi A., Al Otaibi A.H., Al-Baradi A.M., Almalki A.S.A., Algarni S.A., Atta A.A. (2020). "Exploring the optical properties of lead zinc sulfide photoanodes for optoelectronics". Applied Physics A. Sayı: 126(9), s.726.

Beard M.C., Luther J.M., Nozik A.J. (2014). "The promise and challenge of nanostructured solar cells". Nature Nanotechnology. Say1: 9, s.951-954.

Chen L.C., Tien C.H., Liao W.C. (2011). "A phosphor-free white light-emitting diode using $\mathrm{In} 2 \mathrm{O} 3$ : Tb transparent conductive light converter". Journal of Physics D: Applied Physics. Say1: 44(16), s.165101.

Chen P.C., Shen G., Sukcharoenchoke S., Zhou C. (2009). "Flexible and transparent supercapacitor based on In2O3 nanowire/carbon nanotube heterogeneous films". Applied Physics Letters. Say1: 94(4), s.043113.

Chen S., Paulose M., Ruan C., Mor G.K., Varghese O.K., Kouzoudis D. (2006). "Electrochemically synthesized CdS nanoparticle-modified $\mathrm{TiO} 2$ nanotube-array photoelectrodes: Preparation, characterization, and application to photoelectrochemical cells". Journal of Photochemistry and Photobiology A: Chemistry. Say1: 177(2-3), s.177-184.

Dresselhaus M.S., Thomas I.L. (2001). "Alternative energy technologies". Nature, Say1: 414, s.334-337.

Huang Z., Chai C., Tan X., Wu J., Yuan A., Zhou Z. (2007). "Photoluminescence properties of the In2O3 octahedrons synthesized by carbothermal reduction method". Materials Letters. Say1: 61(29), s.5137-5140.

Jia H., Zhang Y., Chen X., Shu J., Luo X., Zhang Z. (2003). "Efficient field emission from single crystalline indium oxide pyramids". Applied Physics Letters. Say1: 82(23), s.41464148.

Jian L., Shihua H., Lö H. (2015). "Metal-catalyzed growth of In2O3 nanotowers using thermal evaporation and oxidation method". Journal of Semiconductors. Say1: 36(12), s.123007.

Jo I.R, Lee Y.H, Kim H., Ahn K.S. (2021). "Multifunctional nitrogen-doped graphene quantum dots incorporated into mesoporous $\mathrm{TiO} 2$ films for quantum dot-sensitized solar cells". Journal of Alloys and Compounds. Sayı: 870, s. 159527.

Kim J., Rim Y.S., Chen H., Cao H.H., Nakatsuka N., Hinton H.L. (2015). "Fabrication of high-performance ultrathin In2O3 film field-effect transistors and biosensors using chemical lift-off lithography". ACS Nano. Say1: 9(4), s.4572-4582.

Latif H., Ashraf S., Shahid Rafique M., Imtiaz A., Sattar A., Zaheer S. (2020). "A novel, PbS quantum dot-Sensitized solar cell structure with TiO2-fMWCNTS nano-composite filled meso-porous anatase TiO2 photoanode". Solar Energy. Say1: 204, s.617-623.

Lin Z.Q., Lai Y.K., Hu R.G., Li J., Du R.G., Lin C.J. (2010). “A highly efficient $\mathrm{ZnS} / \mathrm{CdS} @ \mathrm{TiO} 2$ photoelectrode for photogenerated cathodic protection of metals". Electrochimica Acta. Say1: 55(28), s.8717-8723.

Liu Q., Lu W., Ma A., Tang J., Lin J., Fang J. (2005). "Study of quasi-monodisperse In2O3 nanocrystals: Synthesis and optical determination". Journal of the American Chemical Society. Sayı: 127(15), s.5276-5277.
Padmanathan N., Shao H., McNulty D., O’Dwyer C., Razeeb K.M. (2016). "Hierarchical NiO-In2O3 microflower (3D)/ nanorod (1D) hetero-architecture as a supercapattery electrode with excellent cyclic stability". Journal of Materials Chemistry A. Say1: 4(13), s.4820-4830.

Prashant V. Kamat. (2007). "Meeting the clean energy demand: Nanostructure architectures for solar energy conversion". The Journal of Physical Chemistry C, Say1: 111(7), s.28342860.

Rumble J.R., Bickham D.M., Powell C.J. (1992). “The NIST xray photoelectron spectroscopy database". Surface and Interface Analysis. Say1: 19(1-12), s.241-246.

Schaller R.D., Agranovich V.M., Klimov V.I. (2005). "Highefficiency carrier multiplication through direct photogeneration of multi-excitons via virtual single-exciton states". Nature Physics. Say1: 1(3), s.189-194.

Shen C., Xu N., Guan R., Yue L., Zhang W. (2021). "Highly sensitive ethanol gas sensor based on In2O3 spheres". Ionics. Say1: 27(8), s.3647-3653.

Shen G., Xu J., Wang X., Huang H., Chen D. (2011). "Growth of directly transferable In2O3 nanowire mats for transparent thin-film transistor applications". Advanced Materials. Sayı: 23(6), s.771-775.

Shinde D.V., Ahn D.Y., Jadhav V.V., Lee D.Y., Shrestha N.K., Lee J.K. (2014). "A coordination chemistry approach for shape controlled synthesis of indium oxide nanostructures and their photoelectrochemical properties". Journal of Materials Chemistry A. Say1: 2(15), s.5490-5498.

Singh N., Salam Z., Sivasankar N., Subramania A. (2017). "ZnSe quantum dots sensitized electrospun $\mathrm{ZnO}$ nanofibers as an efficient photoanode for improved performance of QDSSC". Materials Science in Semiconductor Processing. Say1: 64, s.16-23.

Tuzluca F.N., Yesilbag Y.O., Akkus T., Ertugrul M (2017). "Effects of graphite on the synthesis of 1-D single crystal In2O3 nanostructures at high temperature". Materials Science in Semiconductor Processing. Say1: 66, s.62-68.

Tyagi J., Gupta H., Purohit L.P. (2021). "Mesoporous ZnO/TiO2 photoanodes for quantum dot sensitized solar cell". Optical Materials. Sayı: 115, s.111014.

Zhang K., Shen Y., Lin Z., Dong Z. (2021). "Ultra-high ethanol sensitivity sensor based on porous $\mathrm{In} 2 \mathrm{O} 3$ decorated with gold nanoparticles". Materials Science in Semiconductor Processing. Say1: 135, s.106124.

Zou X., Liu X., Wang C., Jiang Y., Wang Y., Xiao X. (2013). "Controllable electrical properties of metal-doped in2o3 nanowires for high-performance enhancement-mode transistors". ACS Nano. Say1: 7(1), s.804-810. 